\title{
A Robust Low-Cost PDMS Peristaltic Micropump WITH MAGNETIC DRIVE
}

\author{
Eleanor Kai ${ }^{1}$, Tingrui Pan ${ }^{1,2}$ and Babak Ziaie ${ }^{1,2}$ \\ ${ }^{1}$ Department of Electrical and Computer Engineering \\ ${ }^{2}$ Department of Biomedical Engineering, University of Minnesota \\ Minneapolis, MN 55414
}

\begin{abstract}
In this paper, we present a low-cost PDMS peristaltic micropump with magnetic drive. The fabrication process is based on soft molding and bonding of three PDMS layers. A base layer incorporates the microchannels while a middle actuating layer houses three miniature permanent magnets covered by a top flat layer. A small DC motor $(6 \mathrm{~mm}$ in diameter and $15 \mathrm{~mm}$ in length) with three permanent magnets $(\mathrm{NdFeB})$ stagger-mounted on its shaft is used to pull down and actuate the membrane-mounted magnets. A maximum flow rate of about $24 \mu \mathrm{L} / \mathrm{min}$ at the speed of $4000 \mathrm{rpm}$ with power consumption of $14 \mathrm{~mW}$ was demonstrated.
\end{abstract}

Keywords: Magnetic Drive, Microfluidics, Micropump, Peristaltic Pump, PDMS, Soft Lithography

\section{INTRODUCTION}

Micropumps play an important role in a wide variety of chemical and biological microsystems, such as drug delivery and microfluidic devices. Over the past decade, several different micropump designs have been developed. These include electroosmotic, nozzle-diffuser, positive displacement, and peristaltic [1-8]. Depending on the pumping liquid and required pumping rate and back pressure, various actuation mechanisms and fabrication techniques can be used. Elecroosmotic pumps have the advantage of high backpressures and simple designs, but require very high voltages and a charged liquid. The nozzle-diffuser pump design is likewise simple and easy to fabricate. Positive displacements pumps require a complex fabrication method for creating two check-valves and an actuating chamber. Several peristaltic pumps have also been demonstrated using various fabrication and actuation techniques such as thermopneumatic, piezoelectric, electrostatic, and magnetic. Piezoelectric drives require high voltages, whereas, for electrostatic actuation one needs to create small gaps complicating the fabrication process. Magnetic drives can provide large forces over extended displacements. However, one frequently needs to integrate microcoils and ferromagnetic materials.

In this paper, we report on the design, fabrication, and test of a simple low-cost PDMS peristaltic micropump with magnetic actuation. Figure 1 shows a perspective view of the PDMS micropump. It consists of three PDMS layers; the bottom one incorporates the microchannel while the middle layer houses three small permanent magnets loaded in small reservoirs separated from the microchannels by a thin PDMS layer (membrane). Finally, a top flat sheet covers the magnets and seals the middle layer. Positioning another set of three magnets at different phase angles on the rotor of a small DC motor creates the serial membrane actuation needed for a peristaltic pump. The polarity of adjacent magnets in the reservoir is reversed in order to prevent simultaneous actuation of two neighboring magnets. By varying the rotation speed the flow rate can be easily adjusted. The micropump has a small power consumption $(<20 \mathrm{~mW})$, mainly determined by the power requirements of the small DC motor.

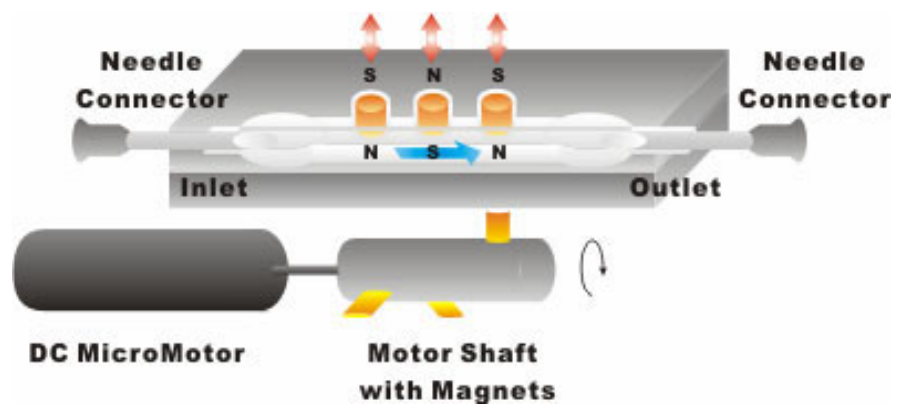

Figure 1. A perspective view of the PDMS micropump.

\section{DESIGN AND FABRICATION}

Figure 2 shows the expanded diagram of the micropump. Silicone elastomer (Ellsworth Adhesive, WI) is the only structure material used for the body of the pump. The first fabrication step is creating two separate molds, one for the microfluidic channel and one for the actuation membranes (middle layer). The top layer is a simple sheet and does not require any mold.

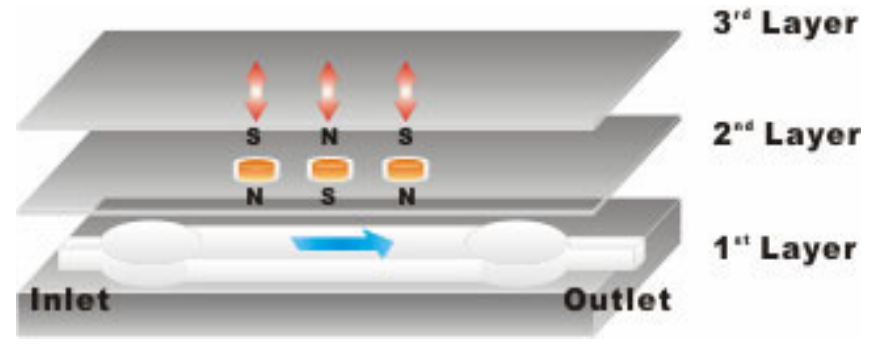

Figure 2. Expanded diagram of the micropump. 
The design used in this paper, which is for $2 \mathrm{~mm}$ square magnets, incorporates a $13 \mathrm{~mm} \times 3 \mathrm{~mm}$ channel with $300 \mu \mathrm{m}$ $x 8.5 \mathrm{~mm}$ needle insertion points at both ends. The middle layer includes $300 \mu \mathrm{m} \times 3 \mathrm{~mm} \times 6 \mathrm{~mm}$ membranes on which three small magnets are attached. The membranes are spaces $1 \mathrm{~mm}$ apart. Alignment marks were also added to assist in bonding the bottom and middle layers.

The mold for casting the PDMS was fabricated using SU-8 (2100, MicroChem Corp., MA). SU-8 was processed according to the recommended directions, but particular care was taken to keep its thickness as uniform as possible. Bubbles were found to form in the photoresist during spinning, but if these were punctured, the photoresist healed after sitting for 10 minutes. Due to the long required bake time, the wafers were rotated every 5 minutes. As an additional measure, the wafers were overexposed by $80 \mathrm{~mJ} / \mathrm{cm}^{2}$ on top of the $550 \mathrm{~mJ} / \mathrm{cm}^{2}$ recommended for the desired thickness $(250 \mu \mathrm{m})$ to prevent structures detaching from the wafer during development. The final molds were found to have a height variation of $200 \mu \mathrm{m}$ to $385 \mu \mathrm{m}$ across the wafers.

PDMS (Silgard 184, 10:1 ratio) was subsequently mixed and cast over the SU-8 mold. For the fluidic channel PDMS layer, $800 \mu \mathrm{m}$ spacers were used whereas for the actuation PDMS layer $650 \mu \mathrm{m}$ spacers were employed to ensure a membrane thickness of at least $250 \mu \mathrm{m}$ (thinner membranes were hard to release from the mold without tearing). Next a transparency was slowly placed on the uncured PDMS, taking care to not introduce bubbles into the film and a $2 \mathrm{lb}$ weight was placed on top of the mold and spacer to achieve the desired PDMS layer thickness [9]. This set up was heated to $100^{\circ} \mathrm{C}$ in an oven for 15 minutes to speed up the curing process. To prevent the SU-8 molds from cracking and buckling during this step, the oven had to be ramped up slowly from $55^{\circ} \mathrm{C}$ to $100^{\circ} \mathrm{C}$ before curing for 15 minutes and then ramped back down to $55^{\circ} \mathrm{C}$. Immediately after curing, the two PDMS surfaces were exposed to the oxygen plasma (100W, $100 \mathrm{mTorr}$ for $30 \mathrm{sec})$ and bonded by applying a pressure of $0.1 \mathrm{MPa}$ [9]. After bonding, the PDMS was heated to $200^{\circ} \mathrm{C}$ for 5 minutes to drive out moisture and strengthen the bond.

Magnets were marked (to indicate poles) and loaded into the membrane chambers. By varying the magnet polarity in adjunct chambers, the interference of magnet-actuated membrane motion is minimized. Finally, the magnets are encapsulated in the chambers by a top PDMS layer and 27 gauge needles are used to create the interface via the needle insertion points provided in the pump's design. Figure 3 shows a photograph of the peristaltic micropump loaded with magnets.

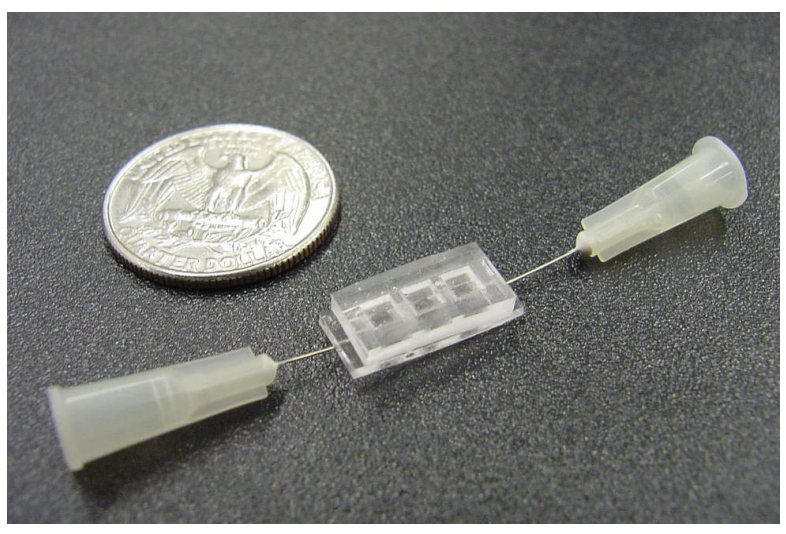

Figure 3. A photograph of the peristaltic micropump loaded with magnets.

\section{EXPERIMENTAL SETUP AND RESUltS}

Figure 4 shows the test and measurement setup. Three external $\mathrm{NdFeB}$ magnets stagger positioned $\left(120^{\circ}\right.$ separation) around the shaft of a $0615 \mathrm{~N} 4.5 \mathrm{~S}$ DC coreless micromotor (MicroMo Electronics Inc., FL, 6mm diameter and $15 \mathrm{~mm}$ length) are used to actuate the internal magnets (Flexible Sheet, ceramic ferrite magnetic powder with flexible thermoplastic binder, Dexter Magnetics). The separation between the external and internal magnets is $1 \mathrm{~mm}$. The external magnets are mounted on the shaft of the DC motor using Polyvinylsiloxane (Coltène Whaledent, $\mathrm{OH}$ ) molded into a cylinder. The pump was placed on the surface of a plastic box that houses the micromotor. This provides an easy way to place the pump over the rotating magnets while protecting the micromotor from any accidental water damage. The pump was primed by water before performing the measurements.

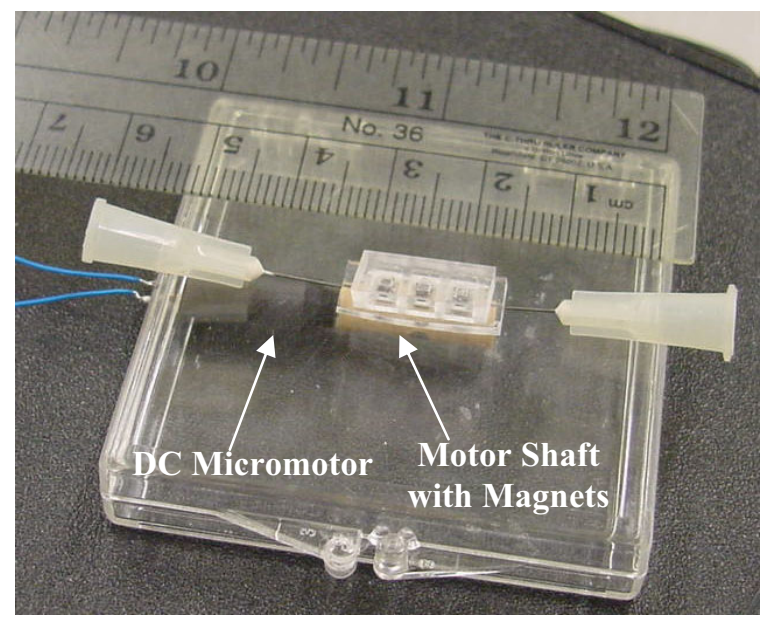

Figure 4. Test and measurement setup. The external magnets are positioned at different phase angles to generate a waveform channel membrane movement. 
Pumping rate measurements were made at pump level by measuring the amount of water that entered the pump over a 15 minute time period using a $1 \mathrm{~mL}$ syringe. Voltage and current measurements were also taken during this 15 minute time period. Motor speed can be roughly estimated using the speed constant given by the manufacturer $(4727 \mathrm{rpm} / \mathrm{V})$. Figure 5 shows the pumping rate vs. the speed of the micromotor. As expected, at lower frequencies the flow rate follows an approximately linear relation to the rotation speed. However, at higher frequencies this relationship caps and eventually drops. This happens when the driving frequency approaches and exceeds the mechanical oscillation frequency of the structure (i.e., membrane) itself. Power consumption versus rotation speed was calculated from the current and voltage measurements, Figure 6. For this particular pump, a maximum flow rate of about $24 \mu \mathrm{L} / \mathrm{min}$ at the speed $4000 \mathrm{rpm}$ with a power consumption of $14 \mathrm{~mW}$ was obtained. The micropump power consumption is rather low compared to other reported pumps most having power consumptions of $>$ $100 \mathrm{~mW}$. An additional advantage of our pump is its low operating voltage $(<1 \mathrm{~V})$ making it suitable for portable battery powered applications.

We also conducted several tests to measure the pumping backpressure. For these measurements, the inlet needle was connected to a reservoir of water via a primed tube while the outlet needle was connected to a tube raised to various heights. A graph of pumping backpressure versus rotation speed is shown in Figure 7. As can be seen, the backpressure is rather low. This is due to the back flow associated with the incomplete closure of the microchannel by the actuating membrane. This can be remedied by a modified design using a stronger magnet and a better alignment. As mentioned previously, although the external magnets were $\mathrm{NdFeB}$, the internal ones were of lower strength magnetic flexible sheets. This was chosen to simplify the loading process. Using $\mathrm{SmCo}$ or $\mathrm{NdFeB}$ internal magnets will increase the flow rate and backpressure. This, however, has to be done by changing the design to allow for tighter holding chambers in order to restraint the strong attraction of the internal magnets during the loading process. Figure 8 shows an improved design allowing the usage of stronger internal magnets. As can be seen, four layers are used in this design with the bottom layer again serving as the microfluidic channel. A flat PDMS sheet will serve as the membrane whereas another layer with cylindrical holes will be used to hold and restrain the magnets. A top layer will be used to seal the device as was in the case for the described micropump.

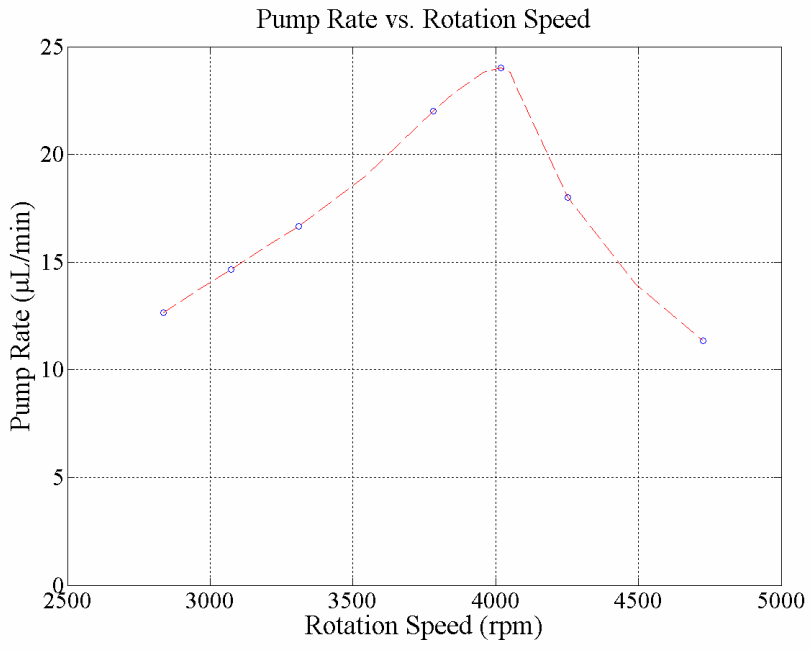

Figure 5. Pumping rate vs. motor rotation speed.

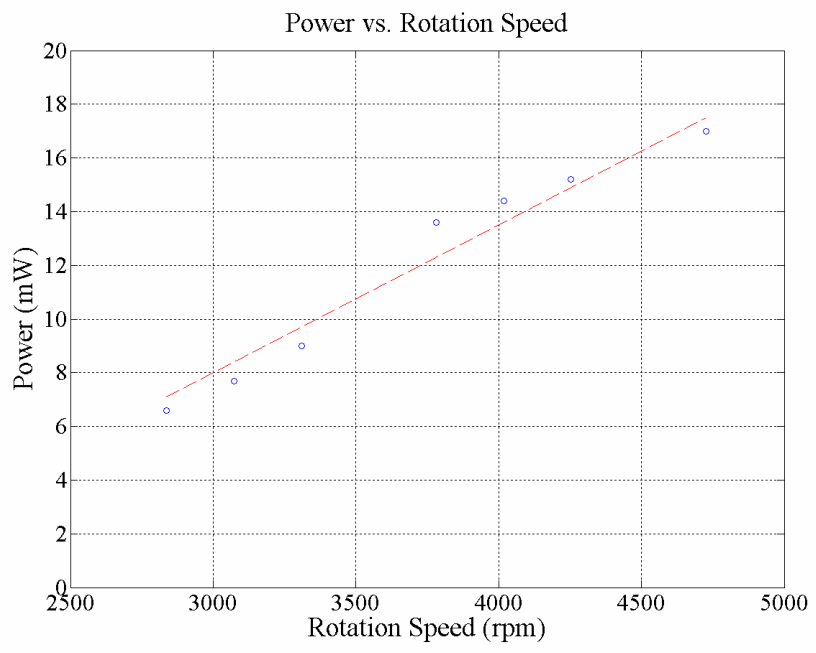

Figure 6. Power consumption vs. motor rotation speed.

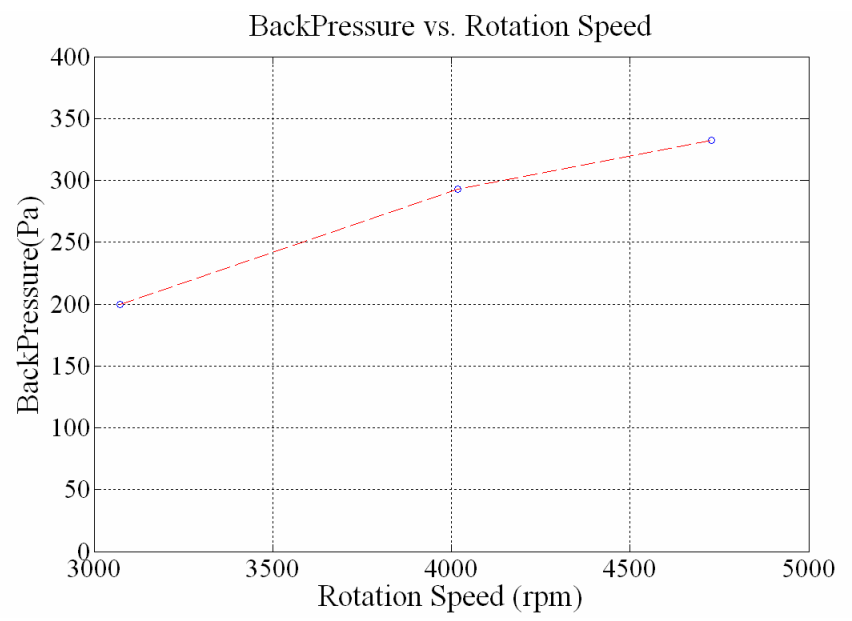

Figure 7. Pumping backpressure vs. motor rotation speed. 


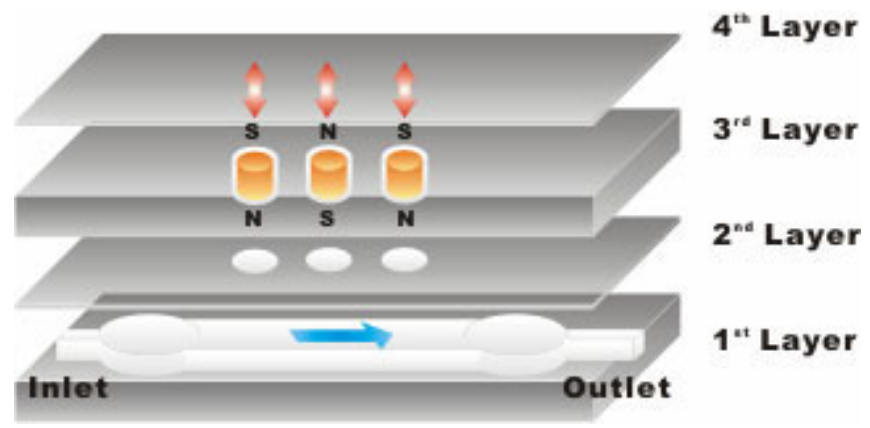

Figure 8. Improved design for higher backpressures and pumping rates.

\section{CONClusions AND FUTURE WORK}

In this paper, we reported a low-cost peristaltic PDMS micropump with a magnetic drive. The pump is fabricated using three PDMS layers. Actuation is achieved using three external magnets attached to a micromotor pulling down three internal magnets loaded in small reservoirs and separted from the microchannel by a thin membrane. The maximum pump rate was found to be $24 \mu \mathrm{L} / \mathrm{min}$ with a maximum backpressure of $300 \mathrm{~Pa}$. The power consumption at this pumping rate is $14 \mathrm{~mW}$ which is one of the lowest reported in the literature. Future work includes design improvements and optimizations to achieve higher backpressures and flow rates.

\section{ACKNOWLEDGEMENT}

The authors would like to thank Mr. Scott McDonald and Mr. Woohyek Choi for their help with fabricating the device. We also would like to thank Mr. Kevin Roberts for helping to dice the magnets.

\section{REFERENCES}

[1] D. J. Laser, A. M. Myers, S. Yao, K. F. Bell, K. E. Goodson, J. G. Santiago, T. W. Kenny, "Silicon Electroosmotic Micropumps for Integrated Circuit Thermal Management", IEEE Transducers Conference 2003, Boston, MA, pp. 151-154, 2003.

[2] A. Olsson, P. Enoksson, G. Stemme, E. Stemme, "Micromachined Flat-Walled Valveless Diffuser Pumps", Journal of Microelectromech. Systems, vol. 6 (2), pp. 161-166, 1997.

[3] J.-H. Tsai and L. Lin, "A Thermal-Bubble-Actuated Micronozzle-Diffuser Pump", Journal of Microelectromech. Systems, vol. 11 (6), pp. 665-671, 2002.

[4] M. Khoo and C. Liu, "A Novel Micromachined Magnetic Membrane Microfluid Pump”, IEEE EMBS International Conference 2000, Chicago, IL, pp. 23942397, 2000.

[5] F. C. M. van de Pol, H. T. G. van Lintel, M. Elvenspoek, and J. H. J. Fluitman, "A Thermopneumatic Micropump Based on Microengineering Techniques, "Sensors and Actuators A, Vol. 21-23, pp. 198-202, 1990.

[6] C. Grosjean and Y.-C. Tai, "A Thermopneumatic Peristaltic Micropump", IEEE Transducers Conference 1999, Sentai, Korea, pp. 1776-1779, 1999.

[7] L. Cao, S. Mantell, D. Polla, "Implantable Medical Drug Delivery Systems using Microelectromechanical Systems Technology", Conf. on Microtech. in Medicine and Biology, 2000, Lyon, France, pp. 487-490, 2000.

[8] S. Na, S. Ridgeway, and L. Cao, "Theoretical and Experimental Study of Fluid Behavior of a Peristaltic Micropump", IEEE Microelectronics Symposium, 2003, Boise, ID, pp. 312-316, 2003.

[9] B. H. Jo, L. M. Van Lerberghe, K. M. Motsegood, D. J. Beebe, "Three-Dimensional Micro-Channel Fabrication in Polydimethylsiloxane (PDMS) Elastomer", Journal of Microelectromech. Systems, vol. 9 (1), pp. 76-81, 2000. 